\title{
Differential Thermal Analysis of Polytetraoxane Obtained by Radiation-Induced Polymerization in the Solid State
}

\author{
Yoshiaki NAKASE and Isamu KurIYAMA \\ Takasaki Radiation Chemistry Research Establishment, Japan Atomic \\ Energy Research Institute, Takasaki, Japan.
}

(Received August 15, 1972)

\begin{abstract}
Differential thermal analysis was carried out on poly(oxymethylene) [polytetraoxane] obtained by radiation-induced polymerization of tetraoxane in the solid state. The profile of the melting endotherm is related mainly to the polymer yield and the melting point mainly to the molecular weight of the polymer obtained. The degradation of the polymer chain during the polymerization in air causes the destruction of the polymer crystal formed already, and produces various types of crystallite in the view of the melting behavior.

Polytetraoxane crystals are easily annealed above $160^{\circ} \mathrm{C}$, i.e., at the temperature range from 160 to $170^{\circ} \mathrm{C}$ crystals of higher melting point are obtained after rearrangement; at the range from 170 to $180^{\circ} \mathrm{C}$, a new endotherm, probably of the new crystal formed after the partial melting, is observed at about $165^{\circ} \mathrm{C}$, and at the range from 180 to $187^{\circ} \mathrm{C}$, a single endothermic peak, probably of the crystal formed after the wide range partial melting, is observed at a lower temperature than that of the melt-crystallized sample. It is suggested that the original polymer crystal may be of the extended chain structure which the crystal rearranges, and that the new crystal formed after the annealing above $170^{\circ} \mathrm{C}$ may be of the folded chain structure.

KEY WORDS Polytetraoxane / Degradation / Differential Thermal Analysis / Melting / Annealing /
\end{abstract}

In a previous paper, ${ }^{1}$ it was reported that in the radiation-induced postpolymerization of tetraoxane in the solid state the polymer yield increased with the polymerization time to reach its limiting value, which was higher in air than in vacuo. The molecular weight of polymers obtained in vacuo increased monotonically with the polymerization time, whereas that of polymers obtained in air was sharply reduced after attaining a maximum value when the polymerization time increased. Furthermore, when air was introduced in the course of the postpolymerization in vacuo, a remarkable decrease in the molecular weight of the polymers was observed after the introduction of air, while the polymer yield increased to almost the same value as that attained when the polymerization was carried out in air for the whole period. In order to clarify the phenomena, the fractionation of the polymers was carried out by the method of fractional precipitation by stirring. ${ }^{2}$ It was found ${ }^{3}$ that the molecular weight distri- bution $\left(I_{\mathrm{p}}\right)$ curve moved to the higher molecular weight side when the average molecular weight of the original polymers was increasing. Contrariwise, the decrease of the average molecular weight made the $I_{\mathrm{p}}$ curve move to the lower side, which corresponded to the disappearance of the high molecular weight fraction which was previously present. It was concluded from the fact mentioned above that the decrease in the molecular weight in the postpolymerization of tetraoxane is attributed to the degradation of the polymer in the presence of oxygen or air.

It has been suggested that polytetraoxane was of the extended chain crystal, because no diffraction intensity peaks are observed by the Xray small-angle diffraction studies. ${ }^{4}$ On the contrary, it has also been reported that X-ray small-angle scattering of the unannealed sample revealed a long spacing of $83 \mathrm{~A},{ }^{5}$ which may suggest the existance of lamella crystals. On the other hand, fibrils were formed in the 


\section{Y. NAKAse and I. Kuriyama}

radiation-induced polymerization of tetraoxane by the solid-state, and lemallae were observed in the samples which were preirradiated at $-78^{\circ} \mathrm{C}$, rapidly molten and then postpolymerized at $100^{\circ} \mathrm{C} .^{6}$

Therefore, we have been interested in studying the morphology of polytetraoxane, because the degradation of the polymer may cause the change in the morphology and crystal growth of polymers formed. The present investigation was started to study the melting behavior of polytetraoxane, as-polymerized and annealed by means of differential thermal analysis.

\section{EXPERIMENTAL}

Polytetraoxane was prepared by $\gamma$-ray induced polymerization in the solid state. The preparation of tetraoxane and the polymerization condition were described elsewhere. ${ }^{1}$ The reduced viscosity was taken as a measure of the molecular weight of polymers. The solution viscosity was determined in $0.3-\% p$-chlorophenol solution containing 2-\% $\alpha$-pinene.

The apparatus for DTA(ARC-2D) was manufactured by AGNE Research Center Co., Ltd. (Japan). A small amount of the sample (less than $1.0 \mathrm{mg}$ ) was weighed out by the Cahn Electrobalance and wrapped carefully with an aluminum foil, $7 \mathrm{~mm}$ diameter and $20-\mu$ thickness. It was placed rather tightly on the top, $c a .1 \mathrm{~mm}$ diameter, of a chromel-alumel thermocouple, $0.3 \mathrm{~mm}$ diameter. On the other hand, only the aluminum foil was similarly placed as a reference on the top of the other thermocouple. There were the sample and the reference, respectively, on the top of a thermocouple at the center of the chamber, $5 \mathrm{~mm}$ diameter and $5 \mathrm{~mm}$ depth. The measurements have been performed always under the nitrogen atmosphere to prevent polymers from decomposition, otherwise the polymer will decompose at the same time with the melting in air. Similarly, the annealing of the sample has been performed mainly in the DTA apparatus under nitrogen atmosphere.

After a given annealing time at a desired temperature, the sample was taken out of the oven to cool on aluminum plate at room temperature. The heating rates used were 1, 2, 3, $5,10,20$, and $30^{\circ} \mathrm{C} / \mathrm{min}$, respectively, and mainly $20^{\circ} \mathrm{C} / \mathrm{min}$. The instrument was calibrated with two pure substances of the benzoic acid, (NBS 39i) and indium (spectroanalytical grade, Johnson Matthey Co.) whose known melting points covered the range $121-156^{\circ} \mathrm{C}$.

\section{RESULTS AND DISCUSSION}

Figure 1 shows the results of the postpolymerization, the reduced viscosity $\left(\eta_{\mathrm{sp}} / C\right)$ of the polymers decreases rapidly to about one half $2 \mathrm{hr}$ after the introduction of air, and to about one sixth $10 \mathrm{hr}$ after the introduction. The heating curves for the various samples are shown in Figure 2, namely $A$ ) the polymer obtained just before the introduction of air, B) the polymer obtained $2 \mathrm{hr}$ after the introduction of air, the molecular weight decreasing to about one half of the original (A), C) the polymer obtained $8 \mathrm{hr}$ after the introduction of air, the molecular weight decreasing to about one fourth, and D) the polymer obtained $72 \mathrm{hr}$ after the introduction of air, the molecular weight decreasing to about one tenth. The melting endotherms shift to lower temperature, and become very broad, especially the onset of the endotherm which moved to a low temperature $\left(c a .100^{\circ} \mathrm{C}\right)$, when the polymerization time was increased after the introduction of air, or with the decrease of molecular weight of polymer obtained. They suggest that the morphology of the polymer

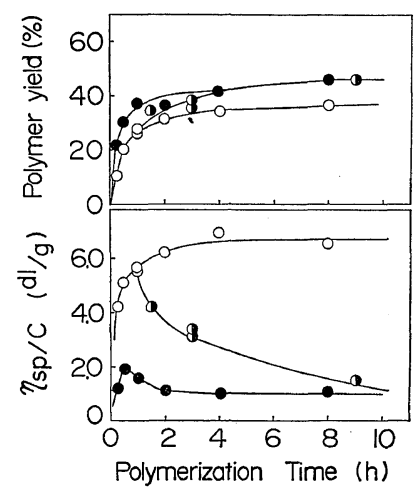

Figure 1. Effect of air introduced in the course of the postpolymerization of tetraoxane: preirradiation, $0.1 \mathrm{Mrad},-78^{\circ} \mathrm{C}$ in vacuo; polymerization temp, $105^{\circ} \mathrm{C} ;(\bigcirc)$ in vacuo; $(\bullet)$ in air; $(\bigcirc)$ air introduced; $1 \mathrm{hr}$ after the start of polymerization so that the pressure attained atmospheric pressure. 
obtained is affected drastically by the polymerization condition or by the degradation of the polymer chain.

In order to understand the profile of the melting endotherms with the changes of polymer yield and molecular weight, the following experiment was performed. Polymerization conditions and the results of the polymerization are listed in Table I.

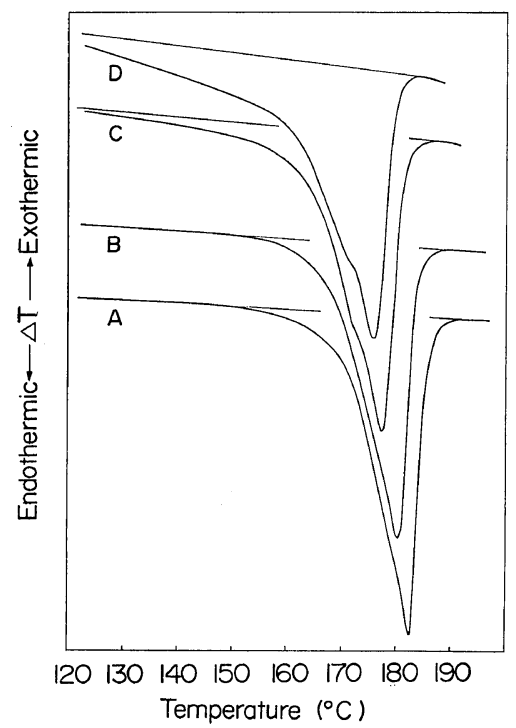

Figure 2. Melting endotherms of polytetraoxane obtained after the introduction of air in the course of polymerization in vacuo. (From Figure 1): heating rate, $20^{\circ} \mathrm{C} / \mathrm{min}$; sample weight, $0.37 \pm 0.01 \mathrm{mg}$; $A$, polymer obtained just before the introduction of air; B, polymer obtained at $2 \mathrm{hr}$ after the introduction of air; $\mathrm{C}$, at $8 \mathrm{hr}$ after the introduction; $\mathrm{D}$, at $72 \mathrm{hr}$ after the introduction.
Effect of Molecular Weight at a Constant Polymer Yield

Figure 3 shows that when the molecular weight of polymer increases, the onset and the peak of the endotherm shift to higher temperatures and the profile of the double melting endotherm becomes clearer. It had already been determined that the molecular weight distribution became broad showing the increase of the higher

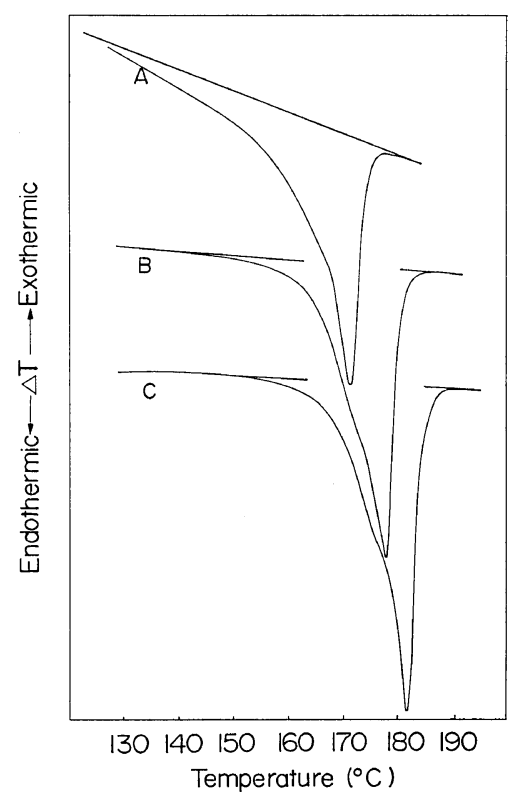

Figure 3. Melting endotherms of polytetraoxane obtained with various molecular weights at the same polymer yield (11\%): heating rate: $20^{\circ} \mathrm{C} / \mathrm{min}$; sample weight, $0.37 \pm 0.01 \mathrm{mg} ; \mathrm{A}, \eta_{\mathrm{sp}} / c, 0.4 ; \mathrm{B}$, $\eta_{\mathrm{sp}} / c, 1.5 ; \mathrm{C}, \eta_{\mathrm{sp}} / c, 5.5$.

TABLE I. The polymerization conditions and results

\begin{tabular}{|c|c|c|c|c|c|c|c|}
\hline \multirow{2}{*}{$\begin{array}{c}\text { Sample } \\
\text { no. }\end{array}$} & \multirow{2}{*}{\multicolumn{2}{|c|}{ Preirradiation }} & \multirow{2}{*}{\multicolumn{2}{|c|}{ Polymerization }} & \multicolumn{2}{|c|}{ Result } & \multirow{2}{*}{ Note } \\
\hline & & & & & Yield & $\eta_{\mathrm{sp}} / c^{\mathrm{a}}$ & \\
\hline 1 & $10 \mathrm{Mrad}$ & $-78^{\circ} \mathrm{C}$ & $55^{\circ} \mathrm{C}$ & $1 \mathrm{hr}$ in air & $11 \%$ & $0.4 \mathrm{~d} l / \mathrm{g}$ & $\begin{array}{l}\text { Figure } 3 \mathrm{~A} \\
\text { Figure } 5 \mathrm{~A}\end{array}$ \\
\hline 2 & 1 & -78 & 105 & $1 / 12$ in air & 11 & 1.5 & Figure 3B \\
\hline 3 & 0.1 & -78 & 110 & $1 / 12$ in vacuo & 10 & 5.5 & $\begin{array}{l}\text { Figure } 3 \mathrm{C} \\
\text { Figure } 4 \mathrm{~A}\end{array}$ \\
\hline 4 & 0.1 & -78 & 105 & 1 in vacuo & 27 & 5.6 & Figure 4B \\
\hline 5 & 0.1 & -78 & 105 & 8 in $\mathrm{CO}$ gas & 37 & 5.4 & Figure $4 \mathrm{C}$ \\
\hline 6 & 10 & -78 & 55 & 24 in air & 25 & 0.6 & Figure 5B \\
\hline 7 & 10 & -78 & 55 & 192 in air & 36 & 0.5 & Figure $5 \mathrm{C}$ \\
\hline
\end{tabular}

a Estimated molecular weight. $c a .1 \times 10^{4}\left(\eta_{\mathrm{sp}} / c, 0.5\right), c a .4 \times 10^{4}\left(\eta_{\mathrm{sp}} / c, 1.5\right)$, and $2 \times 10^{5}\left(\eta_{\mathrm{sp}} / c, 5.5\right)$. 


\section{Y. NAKASE and I. KuRIYAMA}

molecular weight fraction when the average molecular weight of the sample increased. ${ }^{3}$ The profile of the melting endotherm, therefore, is explicable in terms of the molecular weight and its distribution of polymer used.

When the polymer yield is less than about $15 \%$, the profile of the endotherms of the polymer obtained by the polymerization in air and in vacuo is almost the same, provided that the polymer is of the same polymer yield and molecular weight.

Figure 3 is the case of the low polymer yield of $11 \%$, and comparison has been made with polymers obtained in air and in vacuo at the same time. In the case of the polymer yield of $25 \%$ or $40 \%$, the same result as Figure 3 was obtained with polymers formed in vacuo.

\section{Effect of the Polymer Yield at a Constant Mo-} lecular Weight

In the case of $\eta_{\mathrm{sp}} / c, 5.5$, Figure 4 shows the melting endotherms of polymer obtained in the absence of oxygen with various polymer yields of $10 \%, 27 \%$, and $37 \%$, respectively.

A double melting endotherm is observed, the

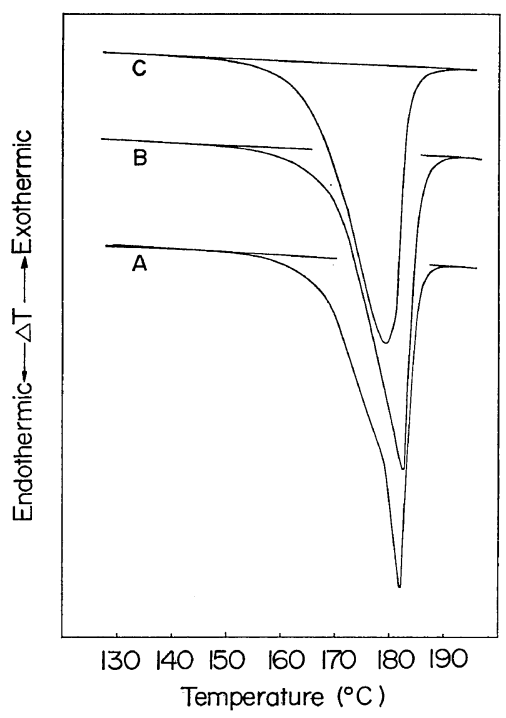

Figure 4. Melting endotherms of polytetraoxane obtained at various polymer yields with the same molecular weight $(\mathrm{I})\left(\eta_{\mathrm{sp}} / C, 5.5 \pm 0.1\right)$ : heating rate, $20^{\circ} \mathrm{C} / \mathrm{min}$; sample weight, $0.37 \pm 0.1 \mathrm{mg}$; A, polymer yield, $10 \%$; B, polymer yield, $27 \%$; , polymer yield, $37 \%$.

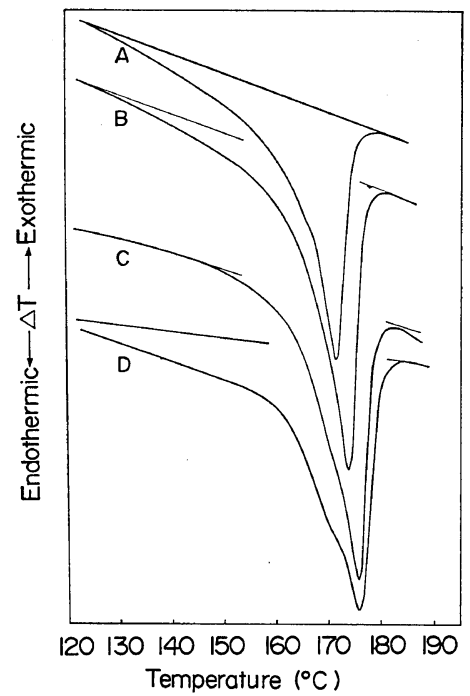

Figure 5. Melting endotherms of polytetraoxane obtained at various polymer yields with the same molecular weight (II) $\left(\eta_{\mathrm{sp}} / C, 0.5 \pm 0.3\right)$ : heating rate, $20^{\circ} \mathrm{C} / \mathrm{min}$; sample weight, $0.37 \pm 0.1 \mathrm{mg} ; \mathrm{A}$, polymer yield, $11 \%$; B, polymer yield, $25 \%$; C, polymer yield, $36 \%$; D, polymer yield, $65 \%$ (the same as $\mathrm{D}$ in Figure 2).

endotherms apparently being converted into a single but broad peak when the polymer yield increases. However, the onset of the endotherm, and the peak temperature of the total endotherm moved only slightly to a lower temperature. The same result was obtained as shown in Figure 5, when the molecular weight is extremely small $\left(\eta_{\mathrm{sp}} / c, 0.5\right)$. This phenomenon may be understood by the relative decrease of the high temperature peak.

As the polymer yield is low, the onset of the melting endotherm is at low temperature, whereas with the increasing polymer yield, the onset moved to a higher temperature. Such a change of profile suggests that the polymer crystal formed becomes uniform, or it contains tightly packed polymer chains, when the polymer yield increases.

The experimental observation is summarized as follows.

(1) The melting endotherm of polytetraoxane is of a double peak. (2) When the molecular weight of the polymer decreases, the onset and the peak temperatures of the endotherm shift to lower temperatures, while the profile of the 
endothermic peak only changes slightly. (3) When the polymer yield increased, the lower temperature peak of a double endotherm becomes intense to give a broad profile.

On considering these observations, the difference in the melting endotherms between $\mathrm{C}$ and $D$ in Figure 5 is noticed at the onset of the endotherm. From the view point of polymer yield, the onset of the endotherm $D$ should be at a temperature higher than that of $\mathrm{C}$, because of the higher polymer yield of D than C. Judging from the endotherm $A$, the onset of $D$ is that of a polymer with a low polymer yield. It has already been found that the polymer giving the melting endotherm $D$ has a rather narrow molecular weight distribution. ${ }^{3}$ Therefore it can be assumed that the polymer crystal formed during the polymerization in air followed by the degradation has the same nature as that formed at the early stage of the polymerization, and that it cannot be of the tight packing of the polymer chains. It is concluded that the profile of the melting endotherm is dependent of the molecular weight and the molecular weight distribution, which affect the morphology of the polymer formed, i.e., the aggregation of the polymer chain, crystallite size and perfection. It is evident that the morphology of the polymer has been changed during the polymerization in air.

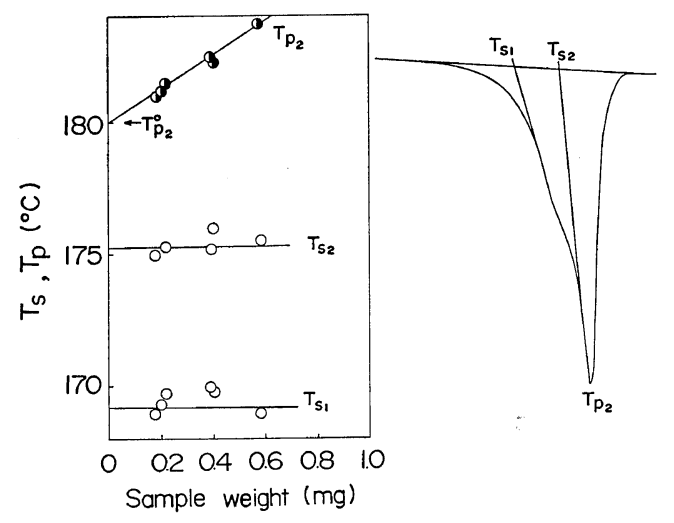

a)

b)

Figure 6. a) Variation of the peak temperature, and the starting temperature of the melting endotherm with the sample weight; heating rate, $20^{\circ} \mathrm{C} / \mathrm{min}$. b) Representation of $T_{\mathrm{p}}$ and $T_{\mathrm{s}}$ (sample, no. 4 in Table I).
In other words, the degradation of the polymer chain during the polymerization in the presence of oxygen occurs in the matrix of the polymer formed.

In order to clarify such a reaction mechanism, it is important to understand the morphological characteristics of the polymer. At first, there is a problem how the melting point of the sample can be determined from the melting endotherm. Figure 6a shows the change of $T_{p}$ and $T_{\mathrm{s}}$ with the increase of the sample weight used, where $T_{\mathrm{p}}$ represents the peak temperature of an endotherm, and $T_{\mathrm{s}}$ the starting temperature of an endotherm both of which are determined as shown in Figure 6b. The suffix is taken for the endotherm from the lower temperature. The polytetraoxane used for this purpose is the same sample as no. 4 in Table I. It is clear that $T_{\mathrm{s}}$ values are constant irrespective of the sample weight used, but $T_{\mathrm{p}}$ becomes higher with the increase of the sample weight used. Ozawa ${ }^{7}$ showed a similar result in the case of benzoic acid. Therefore, it is convenient for us to take $T_{\mathrm{p}}{ }^{0}$, as the extrapolated $T_{\mathrm{p}}$ to the sample weight $0 \mathrm{mg}$, or $T_{\mathrm{s}}$ as the melting point of an endotherm.

Dependence of $T_{\mathrm{p}}{ }^{0}$ and $T_{\mathrm{s}}$ on Heating Rate

Figure 7 shows that $T_{\mathrm{s}}$, especially $T_{\mathrm{s}_{1}}$, becomes higher when the heating rate is less than $10^{\circ} \mathrm{C} /$ min, while $T_{\mathrm{p}}{ }^{0}$ is independent of the heating

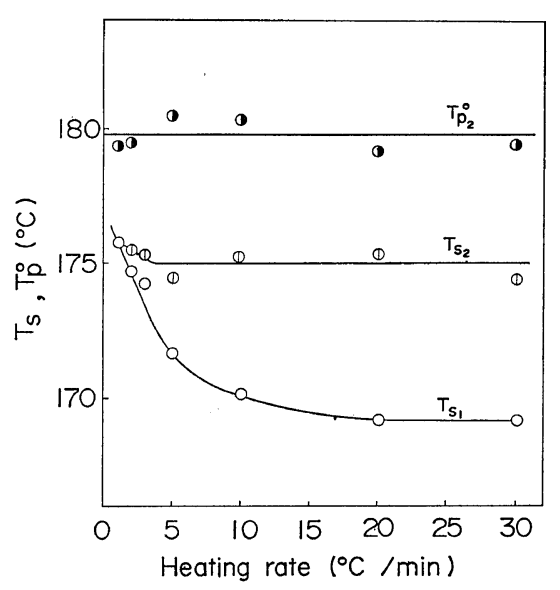

Figure 7. Dependence of the peak temperature $T_{\mathrm{p}}{ }^{0}$ and the starting temperature $T_{\mathrm{s}}$ of an endotherm on heating rate (sample, no. 4 in Table I; sample weight, $0.39 \pm 0.01 \mathrm{mg}$ ). 


\section{Y. NAKASE and I. KURIYAMA}

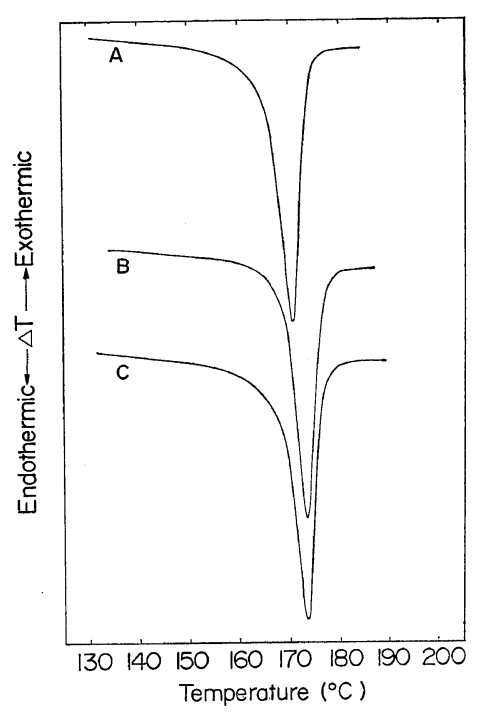

Figure 8. Melting endotherms of polytetraoxane recrystallized from the melt: heating rate, $20^{\circ} \mathrm{C} /$ min; sample weight, $0.40 \pm 0.01 \mathrm{mg} ; \mathrm{A}, \eta_{\mathrm{sp}} / c, 1.5$; $\mathrm{B}, \eta_{\mathrm{sp}} / c, 5.6 ; \mathrm{C}, \eta_{\mathrm{sp}} / c, 15$.

rate. It is suggested that some of the rearrangement in the polymer crystal may take place at the lower heating rate. However, $T_{\mathrm{p}}{ }^{0}$ and $T_{\mathrm{s}}$ should show the same tendency to the heating rate as to each other, if both of them represent the melting point of sample. The difference in the dependence $T_{\mathrm{p}}{ }^{0}$ and $T_{\mathrm{s}}$ on the heating rate may indicate that $T_{\mathrm{p}}{ }^{0}$ and $T_{\mathrm{s}}$ are affected by independent factors, respectively. For example, $T_{\mathrm{s}}$ may give the melting point of the sample used in situ, i.e., reflecting aggregation and perfection of the polymer crystal, etc., while $T_{\mathrm{p}}{ }^{0}$ may show the true melting point of the material when it is a pure and perfect crystal. The details will be discussed elsewhere. ${ }^{8}$

In the case of melt-crystallized polymer, which was prepared by quenching the sample to room temperature from the molten state $\left(190^{\circ} \mathrm{C}, 1 \mathrm{~min}\right.$ under $\mathrm{N}_{2}$ gas), the profiles of the melting endotherms are almost the same, irrespective of the molecular weight of the polymer used as shown in Figure 8. It is clear that the polymer crystallized from the melt shows the same melting behavior with each other even if the molecular weight of polymer is quite different.

It ensures that the morphological structure of the as-polymerized polymer is different from the melt-crystallized one, that is, the structures formed by the large scale organization of the polymer molecule in the course of polymerization is quite distinct from that formed in the melt-crystallized case.

\section{Effect of Annealing}

A) Annealing Temperature. In order to understand the melting behavior of the as-polymerized, the annealing effect was investigated. The polymer used here was of the $\eta_{\mathrm{sp}} / c, 5.6$ (sample no. 4 in Table I), because low molecular weight polymer decomposed during the annealing. Figure 9 shows the melting endotherm of polymers annealed at various temperatures for $10 \mathrm{~min}$. The profile of the endotherms changes clearly with the increase of the annealing temperature.

The influence of the annealing temperature on the melting point was summarized in Figure 10 by $T_{\mathrm{s}}$, the starting temperature of the endotherm, which did not change with the weight of the sample used. From the change of the shape of the endotherms, and hence from $T_{\mathrm{s}}$, it is convenient for discussion purposes to divide the range of annealing temperature into five parts in order to clarify the annealing effect.

(a) In the annealing at the temperature below $160^{\circ} \mathrm{C}$, there is no significant change in the profile, but there are two kinds of aggregation of polymer: one structure gives an endotherm at a lower temperature, and the other at a higher. (b) In the annealing at temperatures between 160 and $170^{\circ} \mathrm{C}$, and endotherm at the lower temperature shifted to a higher temperature and consequently joined to the endotherm at a higher temperature to give a single and sharp endotherm. However, the area of the endotherm corresponding to the enthalpy of fusion remained constant. It may show that the structure giving an endotherm at a lower temperature is easy to rearrange to form the other aggregation to give an endotherm at a higher temperature. (c) In the annealing at the temperature between 170 and $180^{\circ} \mathrm{C}$, quite a new endotherm begins to appear at the lower temperature and it shifts to the higher temperature and has a larger area with the increase of annealing temperature, while the endotherm at the higher temperature shifts to still higher, but the area decreases. 
The total area surrounded by the base line and the endotherm decreases with the increase of annealing temperature. The endotherm at the lower temperature should correspond to the

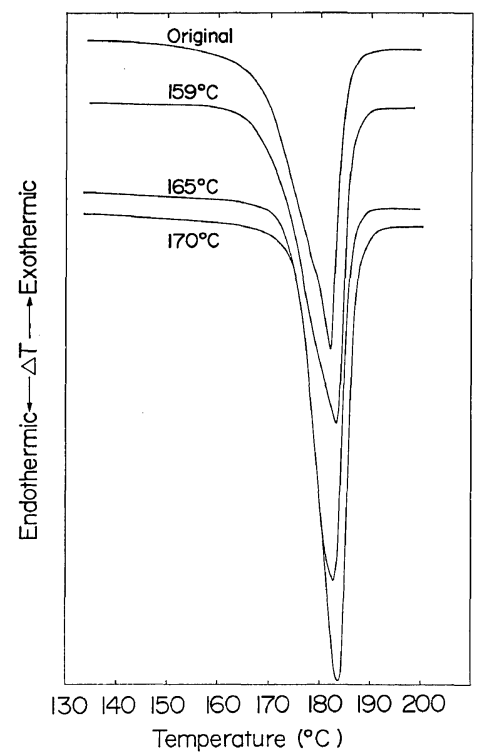

a)

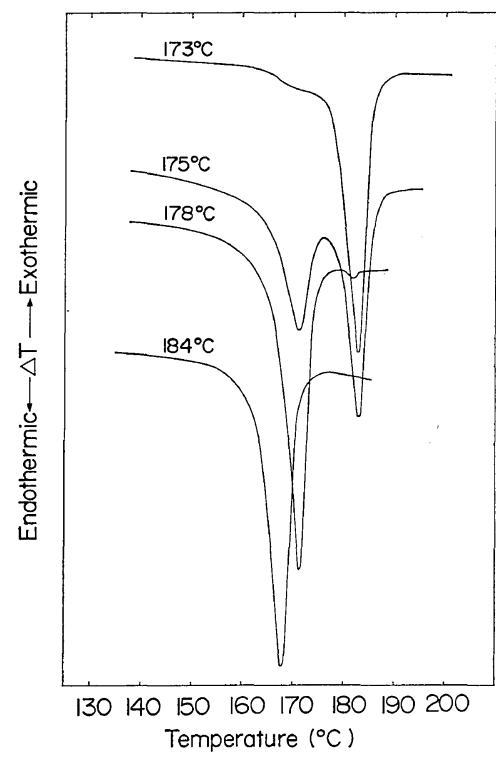

b)

Figure 9. Melting endotherms of polytetraoxane annealed for $10 \mathrm{~min}$ at various temperatures: heating rate, $20^{\circ} \mathrm{C} / \mathrm{min}$; sample, no. 4 in Table I; sample weight, $0.39 \pm 0.01 \mathrm{mg}$. Annealing temperatures are indicated in the figure.

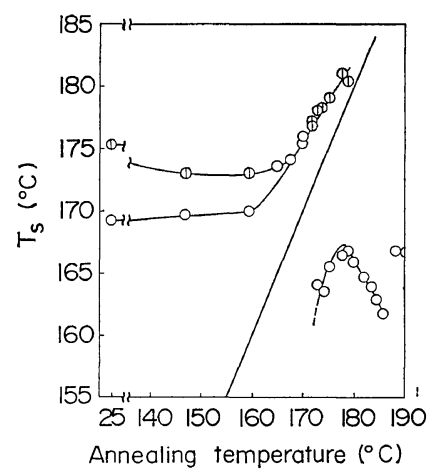

Figure 10. Effect of annealing on the melting point, $T_{\mathrm{s}}$, of the polytetraoxane: heating rate, $20^{\circ} \mathrm{C} / \mathrm{min}$; sample, no. 4 in Table $\mathrm{I}$, annealed for $10 \mathrm{~min}$; sample weight, $0.39 \pm 0.01 \mathrm{mg}$ (from Figure 9).

structure which was recrystallized from the partially molten phase. The fraction of the partial melt during the annealing process increases at the higher annealing temperature, and it recrystallizes on sudden cooling. (d) In the annealing at the temperature between 180 and $187^{\circ} \mathrm{C}$, the endotherm at the higher temperature disappears completely, and the endotherm at the lower temperature shifts still lower at the higher annealing temperature. However, the area surrounded by the base line and the endotherm remains almost constant. It is certain that the structure of the original sample may be kept at a lower level during annealing for $10 \mathrm{~min}$, when the experiment is performed below $187^{\circ} \mathrm{C}$. Therefore, on cooling the sample to room temperature, the loose structure produced a crystal with a melting point lower than the annealing temperature. (e) In the annealing above $187^{\circ} \mathrm{C}$ the molten state is realized, and the recrystallization from the melt forms almost the same kind of crystal irrespective of the annealing temperature in view of the melting behavior.

It is clear that the polymer obtained by postpolymerization cannot be annealed at 105 or $110^{\circ} \mathrm{C}$, even if it is held for a long time.

B) Annealing Time. Figure 11 shows the change of the profile of endotherms of the sample annealed at $165^{\circ} \mathrm{C}$. The polymer used here was of the sample no. 4 in Table I.

The endotherm at the lower temperature shifted to join with the other endotherm at the 


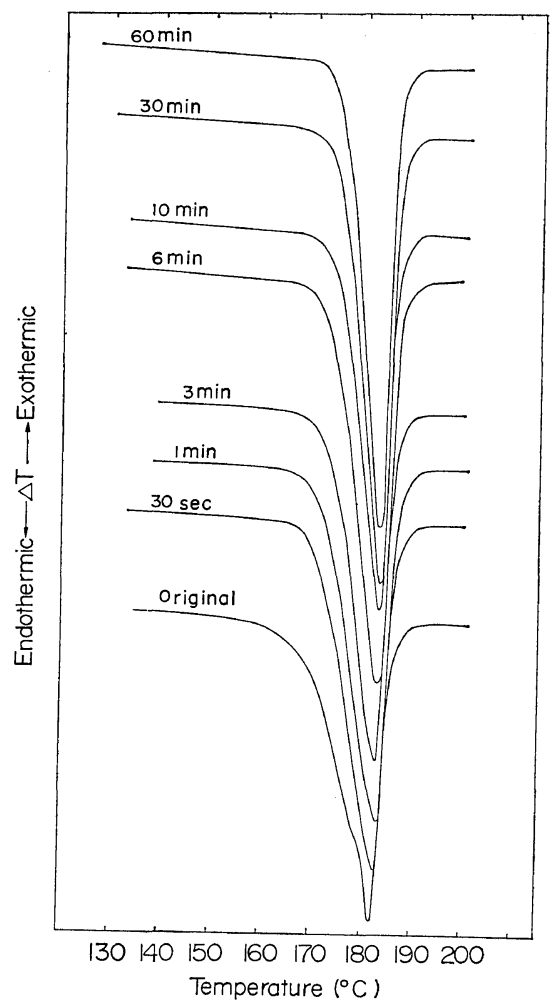

Figure 11. Melting endotherms of polytetraoxane annealed at $165^{\circ} \mathrm{C}$ for various times (I): heating rate, $20^{\circ} \mathrm{C} / \mathrm{min}$; sample, no. 4 in Table I; sample weight, $0.38 \pm 0.01 \mathrm{mg}$. Annealing times are indicated in the figure.

higher temperature even after $30 \mathrm{sec}$ of annealing time. Accordingly, the endotherm become intense and sharp with the increasing annealing time up to $10 \mathrm{~min}$, whereas no remarkable change of the profile of the endotherms could be observed in excess of $10 \mathrm{~min}$. The area of the endotherms increased with annealing time up to $10 \mathrm{~min}$, but became almost constant in excess of $10 \mathrm{~min}$, corresponding to that of the profile change. The greater mobility of the polymer chain may lead to the rapid formation of a new aggregation or crystalline fraction which shows a single and sharp melting endotherm at about $180^{\circ} \mathrm{C}$.

Figure 12 shows the melting endotherms of the sample annealed at $173^{\circ} \mathrm{C}$. The same polymer was used in Figure 11. The profiles of the endotherm changed completely even after $30 \mathrm{sec}$

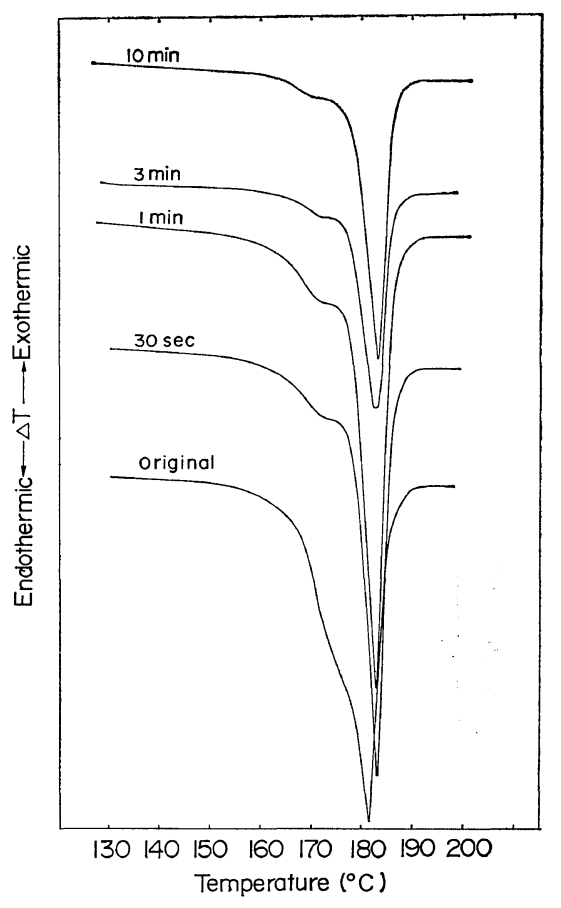

Figure 12. Melting endotherms of polytetraoxane annealed at $173^{\circ} \mathrm{C}$ for various times (II): heating rate, $20^{\circ} \mathrm{C} / \mathrm{min}$; sample, no. 4 in Table I; sample weight, $0.38 \pm 0.01 \mathrm{mg}$. Annealing times are indicated in the figure. The intensity of the endotherms at 3 and $10 \mathrm{~min}$ are one half of others.

of annealing time, but those of the sample annealed longer than $30 \mathrm{sec}$ were not changed so comparably.

The original sample may rearrange quickly at first within $30 \mathrm{sec}$ to form a similar structure to that obtained in Figure 11, in which partial melting may occur during the annealing at $173^{\circ} \mathrm{C}$.

The equilibrium between the aggregation and partially molten phase was obtained, so that almost the same melting endotherm could be observed on the samples annealed in excess of $30 \mathrm{sec}$.

The structure of the crystal formed from the partial melting must be of the folded chain type, but the melting behavior of the original sample and that annealed at the temperature lower than $170^{\circ} \mathrm{C}$ were quite different from that of the sample annealed at higher than $180^{\circ} \mathrm{C}$. Therefore, it can be assumed that the structure 
of the original sample is of the extended chain type.

\section{CONCLUSION}

The change of the melting endotherm with polymer yield and molecular weight is mainly due to the fine structural change during the polymerization. At the early stage of the polymerization, crystals with a high melting point can be formed, but at the later stage, the polymer crystals may be a little different from the crystals formed at the early stage in view of the melting behavior, because the melting endotherm has double peaks when the polymer yield increases. The degradation of the polymer chain is reflected in the change of the melting endotherms which indicates that the degradation reaction by oxygen can take place even in the crystal region. From the fact that the polymer with a low-average molecular weight has rather a narrow molecular weight distribution, ${ }^{3}$ it can be concluded that the crystal formed by the low-molecular-weight polymer chain cannot be of the high melting point. But owing to the accumulation of many kinds of crystallite it can rather easily suffer thermal decomposition even in a $\mathrm{N}_{2}$ atmosphere compared with the higher-molecular-weight polymer, which has been confirmed by thermogravimetry with the polymer of the sample no. 4 in Table $I$ and of $D$ in Figure 2.

It is suggested that the structure of the original polmer, the as-polymerized, is of the extended type, while the structure formed probably from the partial melt by quenching after annealing at the temperature higher than $170^{\circ} \mathrm{C}$ is of the folded type.

The further investigation of the morphology of polytetraoxane as-polymerized is in progress in the temperature ranges of annealing, 160 $170^{\circ} \mathrm{C}, 170-180^{\circ} \mathrm{C}$, and $180-187^{\circ} \mathrm{C}$, respectively.

Acknowledgment. The authors are indebted to Dr. A. Ito for valuable discussions, and to Mr. M. Yoshida for the preparation of the polytetraoxane.

\section{REFERENCES}

1. Y. Nakase, M. Yoshida, A. Ito, and K. Hayashi, J. Polym. Sci., Part A-1, 9, 465 (1971).

2. E. Kobayashi and S. Okamura, J. Appl. Polym. Sci., 12, 1661 (1968).

3. Y. Nakase, M. Yoshida, A. Ito, and K. Hayashi, J. Polym. Sci., Part A-1, 10, 2181 (1972).

4. Y. Chatani, T. Uchida, H. Tadokoro, K. Hayashi, M. Nishii, and S. Okamura, J. Macromol. Sci.Phys., B2, 567 (1968).

5. T. Amano, E. W. Fisher, and G. Hinrichsen, J. Macromol. Sci.-Phys., B3, 209 (1969).

6. A. Munoz-Escalona and G. Wegner, Makromol. Chem. 148, 331 (1971).

7. T. Ozawa, Nippon Kagaku Zasshi (J. Chem. Soc. Japan, Pure Chem. Sect.), 88, 532 (1967).

8. Y. Nakase, to be published. 